IPSI Revista de Investigación en Psicología 1998, Vol. 1, № 2, pp. 75 - 98

\title{
EL PROBLEMA DE LAS MUJERES QUE SUFREN MALTRATO EN LA RELACIÓN DE PAREJA ${ }^{1}$
}

\section{José Vega Gonzáles}

A través del presente estudio se analizan los problemas insertos en las situaciones de violencia doméstica, de pareja y contra la mujer en general, indagando causas y razones por las cuales se producen hechos semejantes en nuestro medio. El análisis incluye detalles referidos a la secuencia de aparición y desarrollo de conductas de maltrato en los individuos mediante su aprendizaje social, y se proponen alternativas y propuestas para la solución de los conflictos basándose en experiencias extraídas de otros países en América Latina y el Caribe. Se subraya especialmente que cualquier tipo de medidas que se adopten deben involucrar aspectos integrales, debido a los múltiples factores que influyen los episodios violentos.

Palabras clave: Violencia física y psicológica, agresión, maltrato, relación de pareja.

Trough the present study we analyze the problems inserted in the situations of domestic violence, couple violence and against women in general, inquiring causes and reasons why happen these facts in our culture. The analysis includes details refereed to the sequence of starting and developments of the behaviors of mistreat in the persons by means of social learning. Alternatives are proposed for the solution of the conflicts based on the experiences extracted of other countries in Latin America and Caribe. It is emphasized specially that any type of prescriptions to be used should consider integral aspects, due to multiple factors that

\footnotetext{
${ }^{1}$ Colaboradores: Juan Morocho, Manuel Campos, Rosa Huerta y María Atalaya.
} 
influence the violent episodes.

Key Words Fisic and psiquic violence, agression, mistreat.

Utilizar el término violencia en vez de agresión resulta adecuado tratándose de la violencia en la pareja o familia, ya que agresión significa ataque, mientras que violentar significa obligar, forzar. Se produce violencia cuando hay una fuerza que se emplea contra el Derecho o ley. La violencia, más que un ataque, es ir contra la voluntad del otro, ir en contra de su libertad.

El problema de la violencia en la pareja se evidencia mayormente en el maltrato hacia la mujer, y este es un tema que fue dejado de lado mucho tiempo por los investigadores de la conducta y por la sociedad en general, posiblemente porque se suponía que la familia era y debía ser un medio cálido y afectuoso. Sin embargo, vemos que es en ella donde se cometen mayores hechos de violencia, incluyéndose homicidios.

En nuestro país explicitar la magnitud del problema es muy difícil, puesto que las víctimas, en su mayoría mujeres, no presentan denuncias. Hace poco tiempo que las mujeres comenzaron a presentar denuncias en la comisaría, pero siempre después de haber sufrido una serie de maltratos continuos.

El concepto de mujeres maltratadas por su pareja incluye además del maltrato físico, el psicológico, en el cual por medio de la manipulación, mentira, humillación o intimidación se somete a las víctimas a una lenta tortura emocional.

La violencia psicológica en las mujeres afecta su salud mental, creando una disminución de sus posibilidades intelectuales y habilidades, pérdida de deseos o interés, depresión y ansiedad pero este maltrato, ya sea físico o psicológico no se da en forma impredecible, muy por el contrario en situación cíclicos, que son necesario conocer y comprender para poderse prevenir.

\section{MUJER Y VIOLENCIA}

El problema de la violencia hacia la mujer en el ámbito familiar ha sido dejado de lado durante mucho tiempo por los investigadores de la 
conducta y la sociedad en general, probablemente debido a que se suponía que la familia era y debía ser un medio cálido, afectuoso y tranquilo. Sin embargo la familia es el lugar en el que más frecuentemente se dan hechos de violencia de todo tipo, incluido los homicidios.

Los medios de comunicación, por las actitudes cotidianas que afectan al ciudadano en la calle e inclusive en su trabajo, debido al reflejo dado por los sectores autoritarios, lo sumergen en una vorágine de tensiones que indudablemente repercuten en su vida diaria.

La violencia cobra fuerza al interior de la familia, en parte como reflejo de las relaciones sociales perturbadas, en un tiempo en donde el hombre ha visto en las mujeres y en los niños un mecanismo que refuerza su cuota de poder.

Nuestra sociedad, como toda sociedad de clases, es violenta porque las relaciones entre dominadores y dominados son relaciones de poder, opresión, autoritarismo y discriminación. Dentro de la estructura familiar predominante en nuestra sociedad (familia patriarcal), el padre (macho) es la cabeza de la familia y por tanto tiene la máxima jerarquía, y por ende se le atribuye el derecho de aplicar las medidas que él considera necesarias para preservar reforzar esa autoridad, conservar la posesión de la esposa e hijos y mantener la unidad familiar así sea fundamentada en el miedo.

En cuanto a las mujeres, éstas ocupan un lugar secundario, ya que en la gran parte de los casos depende económicamente de su compañero, y la dependencia económica determina también que exista en ella una dependencia psicológica e ideológica, respecto al hombre. Sobra decir que en esta pirámide el último y el más bajo escalón lo ocupan los niños, ya que son los más débiles, indefensos y dependientes dentro del grupo familiar. Este tipo de estructura de familia autoritaria y patriarcal facilita el que se presente la violencia intrafamiliar como un fenómeno socioculturalmente tolerado siempre y cuando no exceda el ámbito familiar. Una de las razones por las cuales no se ha abordado el tema con mayor profundidad y mayor primacía es debido a que siempre se le consideró a la violencia en la pareja un problema privado y no público social.

La violencia conyugal e intrafamiliar no se produce ni se desencadena debido a un agente o causa única, sino que son múltiples los factores (intra 
y extrafamiliares, intra e interpersonales), que influyen en su aparición. Hablar de violencia no se refiere únicamente al maltrato físico tangible, sino también en otras formas de agresión menos evidentes pero no por eso menos nocivas, como son el abuso sexual, la tortura psicológica y moral, la denigración, el encierro, etc.

Debemos tener en cuenta que el maltrato de la mujer es el tipo de abuso menos reportado. Nosotros sabemos que los golpes, amenazas e insultos constituyen delitos pero una de las características de estas situaciones es que la mujer no tiene clara consciencia de ellos, y siendo la víctima crónica de delitos cotidianos, sin embargo es ella la que siente vergüenza de lo que pasa y no se anima a hablar ni a denunciar. También siente culpa, pues piensa que en algo está fallando para que le ocurran semejantes cosas. Y si se anima a decido, puede taparse con los mitos sociales acerca de la mujer golpeada: "que ella debe haber provocado al marido", "algo habrá hecho", "que por qué se queda y que si aguanta es porque le gusta". Son los obstáculos y respuestas sociales negativas que impiden aún más la salida de la mujer.

Entre los datos estadísticos con los que se cuenta actualmente, es notoria la observación de que miles de mujeres son abusadas cada año. El abuso ocurre entre gente de todas razas, siendo raramente un incidente aislado. Está acompañado de una subestimación propia, depresión, abuso de alcohol o drogas, problemas emocionales. Este maltrato tiende a aumentarse y volverse más violento con el tiempo. El abuso puede comenzar o incrementarse durante el embarazo, estos hombres, por su posesividad o celos exacerbados, no toleran compartir el afecto y atención de su esposa con nadie, de allí la dificultad cuando aparecen los hijos. El abusador aprendi6 a ser violento creciendo en una familia abusiva. Con respecto al hombre puede señalarse que en su familia de origen ha vivido la desigualdad y el desprecio hacia la mujer, su madre. Ha sido testigo de malos tratos hacia ella en un número significativo de casos, y ha sido él también un niño golpeado.

La mujer golpeada no constituye un cuadro psicopatológico. En algunos casos los trastornos psiquiátricos que se registran se dan a posteriori y como consecuencia de la situación crónica de abuso. 
Cuando la mujer recae en una relación con un golpeador es porque faltó un proceso de recuperación y de reaprendizaje de todo aquello que no se le enseñó desde su nacimiento. Es necesario que comience a pensar en lo que significa ser una persona adulta, responsable de sí misma, autónoma, capaz de tomar decisiones, de ser independiente, de poner límite a los abusos y atropellos de cualquiera, que pueda protegerse y hacer caso de sus derechos En fin, saberse capaz de actuar sin sometimiento.

El fenómeno de la violencia no puede ser comprendido solamente dentro del marco familiar y como un mero producto de las interacciones que se dan en ella. La situación tiene una historia que viene preparándose desde antes de formar el vínculo matrimonial y que depende de la formación, la educación, la ideología acerca del género masculino y femenino que recibió cada individuo. Son problemáticas individuales que luego se sintonizan en el encuentro amoroso, produciéndose, entonces, un acoplamiento entre la mujer preparada para la sumisión y el hombre preparado para el dominio. Esto entre otras cosas indica que la recuperación debe ser individual en primera instancia, para que la mujer se sobreponga a su rol desvalorizado y para que el hombre rehabilite su conducta violenta, aprendiendo otras respuestas a las situaciones que le plantean.

Las mujeres víctimas de violencia cuentan con planes asistenciales, como: atención médica, legal psicológica y casas donde acogerlas. Sin embargo, estos progresos constituyen un paliativo, son una gran ayuda, pero no atacan el fondo del problema.

Es por esto que se ha visto la necesidad de la construcción de un modelo social y cultural en el cual ningún ser humano se sienta con derechos de agredir o abusar de otro, y los hombres y las mujeres recuperen un espacio y un entendimiento donde no haya lugar para discriminaciones ni desigualdades.

\section{VIOLENCIA DOMÉSTICA}

Agresión significa acontecimiento, ataque, es un término más conductual y descriptivo. Violencia indica que más de un ataque, de lo que se trata es ir contra la voluntad del otro, específicamente contra la 
libertad.

Consideramos que hay violencia en la relaciones de pareja cuando un individuo quebranta la integridad física, psicológica o social de otra persona (pareja). Cuando cualquier relación, condición o proceso es impuesto por alguien (agresor) a un otro a quien daña (víctima).

\subsection{Caracterización de la violencia doméstica}

a) Violencia Física: Incluye golpes, empujones, cacheteadas, puñetes, patadas, quemaduras y eventualmente muerte. Este tipo de violencia es la más fácil de visualizar dada su sintomatología y las evidencias externas de su presencia, es la forma más reconocida socialmente y provoca mayor rechazo público por sus características brutales.

b) Violencia Psicológica: Hace referencia a insultos, descalificaciones, amenazas, recriminaciones permanentes, acusaciones infundadas, burlas, humillaciones y todo tipo de agresión verbal. Esta forma de violencia es la de más difícil visualización ya que no deja secuelas externas, lo que implica inexistencia de rastros. Si bien es más útil provoca un impacto más dilatado en el tiempo, por el efecto destructivo de la personalidad, según un estudio realizado en Argentina, algunas mujeres que han dejado relaciones violentas coinciden en señalar que el abuso emocional o violencia psicológica era el que producía los efectos más debilitantes a largo plazo, aunque aquellas mujeres que continúan en la relación violenta les es difícil identificarlo y nombrarlo (Vila de Gerlic, 1987).

Sue Mahan presenta diferentes tipos de agresión dependiendo del nivel: sea psicológico, físico indirecto o físico directo.

\subsubsection{Primer nivel: psicológico}

- Gritar e insultar.

- Disminuir a la persona.

- Permanente mal humor.

- Interrumpe el sueño y las horas de comer. 
- Le prohíbe salir y ver a sus amistades.

- Acoso sexual verbal.

- Amenaza con dejarla o mantener otra relación.

\subsubsection{Segundo nivel: físico indirecto}

- Amenaza con golpear.

- Golpea o tira objetos.

- Destruye la propiedad.

- Maneja agresivamente.

- Amenaza su vida verbalmente.

- Amenaza con arma o cuchillo.

\subsubsection{Tercer nivel: físico indirecto}

- Cachetea o le da nalgadas.

- Muerde o le araña.

- Le golpea con la mano abierta.

- Le quema con cigarro o fósforos.

- Empuja y sacude con fuerza.

- Le golpea con la mano cerrada (puños).

- Le fuerza a tener relaciones coitales violentamente.

- Le golpea con objetos contundentes.

- Le lanza contra objetos o paredes.

- Le provoca asfixia.

- Usa armas de fuego y/o punzo-cortantes.

María Isabel Azevedo incluye el siguiente listado de conductas maltratantes tanto en la Dimensión Sexual del Maltrato como en la Dimensión Afectiva.

\subsubsection{Dimensión sexual del maltrato}

- Asediar sexual mente a la mujer en momentos inoportunos.

- $\quad$ Acusada de infidelidad. 
- Ignorar o negar las necesidades y sentimientos sexuales de la mujer.

- Criticar su cuerpo y su manera de hacer el amor.

- Tocarla de modo desagradable para ella; forzarla a tocarlo ó a mirar lo que ella no desea.

- Salir con otras mujeres.

- Forzar a la mujer a hacer el amor con otros hombres.

- Homicidio, etc.

\subsubsection{Dimensión afectiva del maltrato}

- Insultarla, gritarla, burlarse de la mujer.

- No aprobar jamás las relaciones de la mujer.

- Culparla de todos lo problemas de la familia.

- Amenazarla con violencia.

- Criticarla como madre, amante, profesional.

- Contarle sus aventuras con otras mujeres.

- Crear un ambiente de miedo.

- Hacer que la mujer caiga en depresión.

- Exigir toda la atención de la mujer, compitiendo celosamente con los hijos.

- Amenazarla con malos tratos para los hijos.

\subsection{Causas del maltrato en la relación de pareja}

Este maltrato se presenta con mayor frecuencia (según cuadros estadísticos) del hombre hacia la mujer, por eso es que Mariano Querol plantea: "La violencia del hombre hacia la mujer está en el ambiente, tiene un componente ecológico-cultural". Las causas de la violencia a la mujer están en el problema de relación de pareja donde el hombre asume el rol sádico y la mujer el rol masoquista, surgidos de los impulsos básicos e hipertrofiados para la educación. En relación con la violencia a la mujer, se suelen buscar en ella, las razones por las cuales el hombre la maltrata (porque seguramente es "coqueta", "no comprende a su hombre" o 
"incumple sus labores domésticas") cualquier "falla" de la mujer es esgrimida por el "macho" en contra de su "hembra" frecuentemente con la complicidad de autoridades policiales, vecinos, personal de justicia, médicos legistas, etc. que consideran a la mujer como "causa", esto es portadora de la "razón" para justificar el maltrato. Manifiesta que el hombre aprende, porque le han enseñado que tiene que tratar así a la mujer; no hay razón específica para ello simplemente se la trata mal, porque hay que tratarla mal, porque así es la tradición y las costumbres, que son las que se aprenden, ya que así lo ha visto el hijo en progenitores y así lo va a enseñar este, cuando crezca, a sus hijos. Es importante reiterar, que aunque no se les enseñe violencia de modo específico, los hijos van a aprender, van a ver que el padre comete actos de crueldad, le pega a la madre, y a pesar de eso sigue siendo el jefe y el señor de la casa, ratificando su condición de dueño de la vida de todos. Eso lo aprende sobre todo el hijo hombre, "el hombrecito". A la mujer le enseñan en cambio a someterse, a no responder, a quedarse tranquila, a no hacer nada, el papá llega borracho y les pega a todos, pero todos han de quedarse tranquilos, particularmente "la mujercita". Esas conductas las aprenden los niños y es por eso que el fenómeno de la violencia lamentablemente, se transmite de generación en generación, sin ser hereditario, puesto que es un proceso enseñado. Estos razonamientos se fundamentan en la ignorancia de la psicodinámica de la violencia y en el desconocimiento de un fundamento de la sanidad de la relación humana, y es que nada justifica la violencia intrafamiliar ni de la pareja.

Mariano Querol sostiene que todo condicionamiento cultural es ecobiopsicosocial puesto que lo ecológico, lo biológico, lo psicológico y lo social no son separables. En el proceso educativo que comienza, incluso antes del nacimiento, se enseñan patrones de conducta, que luego se conocen como roles. Es allí donde los padres, particularmente la madre, juegan un papel fundamental en la perennización de la violencia.

La violencia en todas sus formas es iniciada por la violencia intrafamiliar. Esta es particularmente importante puesto que constituye una secuela para todas las formas de violencia y es una fuente para su incremento y perennización. 
Es la cultura la que asigna de antemano un lugar según el género, clase social y raza a que se pertenezca, y la que se va internalizando en las experiencias intersubjetivas. De ahí que sean insuficientes los intentos de cambiar el lugar de subordinación que ocupa la mujer solamente en la esfera social.

En los procesos de socialización a las mujeres y hombres, desde niñas y niños se los educa y se les orienta a través de mensajes implícitos hacia lo que se considera atributos específicos de lo femenino y lo masculino. las diferencias se hacen evidentes a través de las tareas que se les deja, de los valores que se les refuerza, de las cualidades que se les estimula, de los temores que se les infunde y de los límites y presiones que se ejercen sobre ambos de manera diferenciada.

En el caso de los niños, comúnmente se les alienta la curiosidad, se los anima a la exploración, a la conquista de nuevos terrenos, a aparecer fuertes, potentes y dominadores del medio.

En las niñas, se tiende a inhibir su curiosidad como una forma de preservarlas de los peligros de la vida, se las anima a vivir alerta a las necesidades de los otros, por lo general vocación de servicio, abnegación y sometimiento.

María Cristina Vila de Gerlic sostiene que otra de las causas son las creencias sociales que sustentan la violencia contra la mujer. Entre estas tenemos:

\section{a) Valores del rol femenino tradicional}

A una mujer se le dice que debe aceptar pasivamente lo que la vida le ofrece. Algunas de las creencias que contribuyen a que las mujeres golpeadas permanezcan en las relaciones abusivas, y reflejan expectativas esterotipadas por las mujeres en general son:

"El matrimonio no es un lecho de rosas. Hay que tomar lo bueno y lo malo". "Es tu deber apoyarlo. Debe tener problemas".

El entrenamiento para el rol femenino tradicional prepara a la mujer para la posición de víctima. Parte de ese entrenamiento es pensar que es egoísta, si atiende sus necesidades antes que las de los demás. En una relación abusiva corre el riesgo de ser llamada mártir o masoquista cuando defiende 
realmente a su compañero, cuando está sólo haciendo aquello para lo que fue educada. La mujer es presionada para que su matrimonio "funcione o al menos parezca hacerlo". Ella es la responsable del éxito o el fracaso de la unión.

$\mathrm{Si}$ se protege de la violencia yéndose, es acusada de desertar, si permanece es acusada de necesitar el abuso o aún más de obtener placer del mismo. A la mujer golpeada se le crea un gran conflicto ya que fallar en mantener la unión del matrimonio significa fallar en la expectativa central de su rol femenino.

\section{b) La privacidad del hogar}

Nuestra sociedad nos enseña que la familia es un espacio sagrado. nadie que no sea de la familia tiene derecho a intervenir. Se espera la lealtad familiar. lo que pasa tras las puertas es un asunto privado.

"No laves tus trapos sucios en público".

"Esta es mi casa, aquí puedo hacer lo que quiera".

"Yo no me meto en los asuntos privados de una familia".

Estas creencias hacen que vecinos, parientes y amigos aún profesionales no intervengan cuando presencian abuso hacia un miembro de la familia. Aunque es meritoria, en cierto sentido, la idea de la "privacidad del hogar" a menudo se usa como escusa para la irresponsabilidad e inactividad o falta de solidaridad. Esto estimula que las mujeres luchen y sufran en silencio.

\section{c) Acusar a la víctima}

Esta ideología produce tanto daño que merece una consideración especial. Algunas creencias que la reflejan son:

"¿Qué hiciste para que te pegara?".

"Tu marido es amoroso, debes haber hecho algo mal".

"Si no te hubieras casado con él no te hubieras metido en este lío".

Estos juicios alientan la imagen negativa de sí que tienen las mujeres golpeapas. Estimulan sus dudas y las convencen de, que son realmente responsables de la violencia masculina. 


\section{d) La familia de dos progenitores como la familia ideal}

Debido a que la familia con dos progenitores es considerada la ideal, muchas personas sienten que la familia debiera permanecer unida a toda costa. Se otorga un gran valor a la preservación de la tradicional unidad familiar más que a la felicidad y seguridad de los miembros individuales de la familia. También existe la creencia de que los niños necesitan al padre en el hogar, sin tomar en cuenta la calidad de relación o los riesgos que puedan enfrentar con motivos de su presencia.

\footnotetext{
"Debe quedarse con la seguridad de la familia" "El lugar de una mujer es el hogar"

"El es un buen padre aunque le pegue a ella de vez en cuando"
}

Este tipo de ideas determina que las familias permanezcan unidas por motivos equivocados. Los niños no necesitan un padre que ofrezca un modelo de conducta agresiva para solucionar problemas. Presionar a las madres víctimas de abuso para conservar a las familias intactas no sólo pone en peligro su seguridad sino que erosiona su habilidad para cuidar adecuadamente a sus hijos.

\subsection{El maltrato en la relación de pareja: causas y razones de su mantenimiento}

\subsubsection{Ciclo de la violencia}

Para ayudar a quienes viven en una relación violenta se necesita comprender su situación, pero a veces nos resulta difícil comprender las historias de violencia entre marido y mujer, esas historias pueden ser muy exageradas o chocantes, estremecedoras o muy diferentes de nuestra propia experiencia. Puede resultamos muy difícil imaginar cómo una relación de amor puede deteriorarse hasta llegar a la violencia.

\subsubsection{Fases en la relación abusiva}

a) Cortejo. Ella puede ser una adolescente que vive una situación hogareña opresiva o una mujer independiente que está desarrollando su carrera. 
Ella puede sentirse atraída por él porque le parece fuerte, excitante o romántico. Él puede sentirse atraído porque ella le parece frágil, necesitada de protección o porque le parece sexy e independiente. Probablemente tenga una importante atracción sexual.

Él puede ser celoso posesivo con ella. Ella puede encontrar esta situación halagadora y creer que sus celos son una señal del amor de él.

Aunque ambos puedan parecer personas seguras, internamente no lo son. Puede tener baja autoestima. Uno, o ambos, pueden haber vivido violencia en la familia. Juntos se sienten bien.

b) Compromiso. En algún momento de este proceso se convierten en una "pareja". Estén o no legalmente casados, en la convivencia toman los roles tradicionales de marido y mujer. El espera que ella sea "buena esposa" que satisfaga a su marido. Aunque ella pueda ser segura en otras situaciones, con él ella actúa en roles pasivos, tal vez con reconocimiento que hay alguien preocupado por ella. Ambos creen, aunque no lo sepan, que la esposa es responsable de la felicidad del hogar.

Él depende del apoyo emocional de ella, que le cree un medio ambiente cariñoso, y le haga sentir masculina. Ella depende de él para que tome decisiones, sea el dominante, la haga sentir femenina. Ella puede depender económicamente de él. Durante un tiempo las necesidades de ambos se satisfacen. Su mutua dependencia asegura un tiempo de felicidad.

c) Tensión. Las cosas comienzan a cambiar. Puede haber una fuente externa de presión: trabajo, etc., lo más frecuente es que el primer embarazo cambie el clima de la relación.

Ella hace esfuerzos y le cuesta anticiparse a los deseos de él. Él se . siente estafado. Un hombre en su casa debería sentirse en un castillo, y el castillo no aparece .

. Él puede creer que a las mujeres hay que tenerlas "cortas" y comienza a atacarla, verbalmente con insultos, acusaciones, a decirle o ponerle nombres feos. Puede comenzar a controlar a dónde va y qué hace, comienza un abuso emocional. Ella se siente dolorida y confusa. Trata más 
que antes de complacerlo, con las comidas, con su arreglo. Al tratar más de complacerlo se respeta menos a sí misma y se siente responsable. Ambos creen que la responsabilidad es de ella. Él se va poniendo más crítico y más opresor, ella más pasiva y menos segura de sí misma. Ella se siente más culpable. Aumenta la tensión.

d) El primer incidente violento. Durante una discusión, él le pega, ambos quedan estremecidos. Él le pide perdón y le promete que nunca volverá a pasar. El no sabe que le pasó, porqué estaba tan tenso. Ella está de acuerdo con él. Él estaba distinto de como es realmente. Él la quiere, cómo le pegaría, es un hecho aislado.

Él se pone cariñoso, más cariñoso de lo que ha sido en meses. Nuevamente viven momentos de ternura y pasión más intensos en contraste con las emociones violentas. La magia vuelve. No hablan de lo que pasó. No pueden creer que haya pasado. Entonces no pasó. Para qué estropear la frágil armonía.

La identidad de sus emociones y su mutua negación los acercan, lo hacen más independientes el uno del otro. Pero una barrera ha sido cruzada.

e) Pasa nuevamente.- Su cercanía emocional comienza a deteriorarse. Crece nuevamente la tensión. Los insultos y acusaciones comienzan, ella trata más que antes de anticiparse a todo lo que a él le pueda molestar.

Ocurre otro incidente, esta vez no están tan estremecidos cuando él la ataca a ella. Nuevamente él se arrepiente y le dice lo que ella quiere oír. Ella quiere que sea verdad, y por eso le cree. Nuevamente se sienten juntos por un tiempo, otra "luna de miel". estadio de ternura y amor que los en trampa más.

El ciclo se repite más frecuentemente: tensión, violencia, luna de miel. En este momento del proceso ella no piensa que es una mujer víctima del abuso. La realidad duele demasiado y ella la niega. En vez de tomar consciencia de la realidad se siente culpable y trata de adaptarse a él (no puede), trata de que la luna de miel dure más, no dura.

El no se considera un marido abusador, después de todo él la quiere; ella no fue al médico por sus heridas, el no las vio. Piensa que no la lastimó, que sólo la mantiene en su lugar. Ambos inventan excusas para él, él tuvo 
una infancia desdichada, mucha presión en el trabajo estos días, tomó ... Ambos le echan la culpa a ella, si ella hubiera sido más comprensiva, si ella no hubiera dicho las cosa equivocadas, él no hubiera explotado. Ella debería saber mejor qué hacer cuando él esta mal.

Ambos mantienen silencio. No quieren que nadie lo sepa, qué pasa tras las puertas cerradas. Irónicamente cuando más empeore la situación, son más amorosos delante de otras personas y más dependientes el uno del otro.

f) Se establece el patrón. El ciclo continua: tensión, explosión violenta, luna de miel. Los incidentes violentos se hacen cada vez más serios y las lunas de miel más cortas. La ternura y el afecto se expresa ahora durante la luna de miel, después de los golpes. Pero si antes la ternura la hacia creer a ella que él la quería, ahora la siente como otra violación. Y si antes él la mantenía con promesas ("nunca pasará otra vez", ahora él usa amenazas ("te voy a quitar a los niños").

Un día ella piensa "no me pega porque está borracho, sino que toma como una excusa para pegarme". A veces cuando siente los pasos de él que se acerca, ella sabe que esa noche va a ser difícil. Como táctica para sobrevivir la mujer puede provocar luchas inconscientemente quiere acelerar el ciclo para poder terminar con la violación. El la acusa de empujarlo a la violencia. Y a veces ella lo hace, para terminar con la insoportable tensión. El abuso físico puede ser más fácil de tolerar que le emocional y el verbal que le precede. Los de afuera pueden ver como que cualquiera de los dos ocasiona la violencia, en realidad como el carcelero y sus prisioneros, ambos están encerrados en el ciclo de la violencia.

\subsection{Consecuencias de la violencia contra la mujer}

Querol manifiesta que existen costos tanto directos como indirectos: consecuencias mentales graves, suicidio, depresión, ansiedad, disfunciones sexuales, farmacodependientes, complicados del embarazo, bajo peso en recién nacidos entre otros, que hacen más importantes y grave el problema. 


\subsubsection{Consecuencias: la experiencia psíquica de la víctima}

Miedo: Es el sentimiento que aparece predominante. Este gobierna sus acciones y colores cada momento. Incluso los sueños, produce insomnios y pesadillas. Esta descripción del sueño lleva a la dependencia de somníferos u otros. El cónyuge puede haberle amenazado con pedirle o matarle si ella intentaba romper el silencio o hechos más graves si ella pensara dejarlo. Es común escuchar historias como ésta: "mi marido me amenazó con matarme si alguna vez se enteraba, de que planificaba dejarlo". "Me dijo si me dejas te encontraré. No importa cuanto tiempo me lleve. Te agarraré y no te podrás escapar. Te romperé la cara para que nadie vuelva a mirarte. No solo te vaya matar sino que voy a destruir a cualquiera que te ayude a irte. Te mato a ti, a los niños y después me suicido".

Muchas están inmovilizadas por su terror. Esta es la emoción subyacente que explica porque están donde están. Para luchar contra ese miedo siempre presente muchas niegan al horror y la violencia de las amenazas y minimiza su necesidad de seguridad.

Minimizar el abuso: Muchas mujeres víctimas de abuso, especialmente en su primer contacto con el profesional tiende a minimizar la gravedad del abuso. El pensamiento subyacente a esta minimización incluye:

a) El miedo a que hablar empeore su situación.

b) Su falta de información acerca de lo que es abuso y quienes son sus víctimas.

c) Su necesidad de creer que no es tan malo. Como una manera de poder soportar su vida hasta que es lista para luchar contra la realidad y tomar una medida protectora.

d) Ella se avergüenza por el abuso.

e) Ella cree ser responsable por el abuso.

Aislamiento: La mujer golpeada tiene posibilidades de recibir ayuda. $\mathrm{Su}$ 
miedo por la seguridad de las personas que quiere la mantiene inmovilizada. Su vergüenza por los golpes la distancia de la gente. Sus pocos amigos desconocen del terror de su hogar. Aun si ella intenta salir, su compañero sabotea sus esfuerzos al controlar sus actividades y limita sus contactos fuera del matrimonio. Él puede deliberadamente alejarla de su familia y amigos a través de conductas rudas y avergonzantes.

Es difícil que tenga ella un trabajo gratifican te, una ayuda para cuidar a los niños, actividades recreativas o terapéuticas; su aislamiento social limita sus oportunidades de un feedback realista que puede modificar su percepción de su situación. Su soledad incrementa su dependencia de su cónyuge, la persona que promueve su aislamiento. El ciclo esta completo. Ella está forzada aceptar la definición del valor de su persona.

Indefensión: La mujer golpeada está a menudo en un estado de indefención, fenómeno descrito en detalle por Walker. Esto significa que sus intentos de escapar, controlar o evitar la violencia han sido un fracaso. Esto la lleva a un sentimiento de indefensión que determina la creencia de que nada de lo que pueda hacer cambiar la situación.

Numerosos experimentos con varios animales han sido objeto de pruebas. Seligman y sus colegas colocaron a perros en cajas y les aplicaron shocks eléctricos en intervalos impredecibles. Los perros rápidamente aprendieron que hicieran lo que hicieran no podrían controlar los shocks y mostraban signos visibles de apatía. Obediencia pasiva y complacencia eran las características de su carácter. Aún cuando la caja se abría los perros no escapaban para vivir. Para contrarrestar los efectos del experimento eran necesarios esfuerzos para sacar a los perros de las cajas y mostrarles que podían elegir a dónde ir.

Las mujeres golpeadas describen-una experiencia semejante, su falta de control de las situaciones lleva eventualmente a un estado crónico de identificación, falta de esperanza y amarga desesperación, Cuanto más tiempo la mujer ha sido víctima del abuso, más tiempo necesitara para superar los efectos de la indefención.

Intemalización de la culpa: Ella cree en los mitos acerca de la violencia. 
Ella piensa que originó los golpes al haber hecho algo mal. Su cónyuge le dice repetidas veces "¿Por qué haces que te pegue?" "Si hubieras hecho lo que yo te decía esto no hubiera pasado". Ella trata de ser mejor sin darse cuanta de que la violencia no tiene que nada que ver con su conducta o su personalidad.

El pensamiento de la víctima se construye a partir del rol femenino; ella crece creyendo que su rol femenino es su responsabilidad que el matrimonio "funcione", si su marido la maltrate, entonces ella debe haber hecho algo mal. Sus amigos, su familia, los profesionales de la comunidad contribuyen a que ello piense esto. Ella pierde mucho tiempo y energía planificando su vida y sus conversaciones para no irritar a su marido. Es una forma de vida que se describe con la frase "caminar sobre huevos". Sus sentimientos de culpa por la violencia del cónyuge le evitan problemas a él y perpetúan su utilización de la violencia.

Ambivalencia: El compañero violento no lo es siempre. Hay períodos en los que ella siente que él es un compañero cariñoso. Esta es la cruz de su ambivalencia. Quiere que la violencia termine. Ella espera que él cambie. Ella quiere creer en sus promesas: Piensa que ella lo quiere. Su definici6n de amor puede ser diferente a la nuestra pero ésa es la definición por la que ella se rige. A ella también le aterroriza el proyecto de vivir sola. La separación de su cónyuge la llevará a un gran cambio de su estilo de vida. Para ser mujer de clase media o clase alta, la caída del nivel de vida puede ser dramático. Ella deberá enfrentar una ardua adaptación a la nueva situación. Hay barreras reales para el cambio y no sólo para la mujer golpeada, sino para todas las mujeres de nuestra sociedad.

Pocas mujeres, en matrimonio mal venidos (violentos o no) tiene la independencia económica para dejar sus matrimonios sin preocupaciones para autoabastecerse a sí misma y a sus hijos.

Internalización de la opresión: Cuando un grupo cree que es inferir y cree que merece ser maltratado, es más sencillo que el maltrato continúe. Esas creencias sin a veces llamadas "internalización de la opresión". Los mensajes acerca de la inferioridad pueden venir de diferentes fuentes: 
familia, amigos, cuentos infantiles, libros escolares, propagandas, películas. La primera experiencia de victimización se complejiza cuando la victima internaliza su opresión.

La mujer golpeada puede considerarse a sí misma inferior y cuando es golpeada por primera vez esto confirma la sospecha "algo no anda en mí". La mujer que tiene poco apoyo para desafiar el rol femenino tradicional es más vulnerable a permanecer en una relación abusiva. Cuanto más haya internalizado la opresión, más tiempo le llevará superar su victimizacion.

Baja Autoestima: Como consecuencia del abuso repetido y de la victimizacion resulta una baja autoestima. El sentimiento de confianza de la mujer en sí misma y la creencia en sus capacidades han sido dañadas. Lo más humillante para ella es el haber sido golpeada por la persona que eligió para que fuera su marido, la persona que se suponía que la quería y la cuidaría.

Ella describe generalmente después del peor episodio esta traición, cuanto más severo y prolongado es el abuso, más pobre será su auto imaginación. Ella comienza a creer lo que le dicen. En el pasado ella pudo haber amenazado con irse o haberlo hecho por un breve período de tiempo, y haber resuelto no volver a menos que hubiese cambios. Al estar sola, sus miedos y la fría realidad la superan. Sus opciones son limitadas y se ve forzada a volver a una situación que no ha cambiado. Su incapacidad para seguir adelante con su resolución de no volver a su marido la hace sentir más culpable y debilita más su autoestima. Sabe que se fracaso es una victoria para él.

La mujer que voluntariamente vuelve con su marido porque él le prometió cambiar (por ejemplo hacer una terapia) puede sentir algún control sobre su vida. Puede volver con más integridad. Le ha demostrado claramente a su cónyuge que está dispuesta a seguir con él si él modifica su condición violenta.

\subsection{Alternativas y propuestas de solución}

Muchas mujeres violentadas por sus cónyuges han hecho diversos 
intentos que pueden reducirse a:

a) Separarse físicamente vía divorcio o cierre de puertas, lo que no deja de generar violencia, sino más bien la embalsa y hasta intensifica.

b) Mantenerse inmovilizada, detenida, golpeada y tratada como objeto del marido, lo cual perenniza la violencia.

c) Continuar con la violencia y alimentarla a través de más golpes, llegando a un nivel de indiferenciaci6n entre agresor(a) y agredido(a).

En los tres casos, las reacciones generan una violencia desbordada que "las mujeres no podrían parar solas. La posibilidad de cuestionar la dificultad que tiene para poner limites internamente y comprender que son ellas quienes tienen que aprender a establecer desde dentro permitirá otro orden en la dinámica de sus relaciones.

Por otro lado, en casi la totalidad de los países de América Latina y el Caribe existen experiencias de diversa índole que tienen como objetivo enfrentar la violencia contra la mujer, específicamente la violencia que se da al interior de la familia, como puntos de referencia podemos mencionar:

a) Centros de Atención a mujeres golpeadas: Estas iniciativas responden a experiencias parcializadas desarrolladas en primer lugar por organizaciones de mujeres que luego son retornadas e integradas, o por el gobierno, o por organismos no gubernamentales. Enfrentando el problema desde una perspectiva multidisciplinaria.

b) Grupos de autoayuda o de apoyo: Estos grupos se conforman como un espacio de encuentro e identificaci6n entre mujeres que se ven afectadas por situaciones de violencia en la familia y que viven con culpabilidad, baja autoestima, vergüenza y miedo. El objeto básico es que las participantes entre sí se otorguen apoyo afectivo y psicológico para que logren una mayor acertividad y salgan del aislamiento que generalmente sufren. 
c) Casas de Refugio o Albergues: Es otro tipo de enfrentamiento al problema de la violencia doméstica de más reciente creación en América Latina. Los refugios para mujeres maltratadas han sido base de discusión y de cuestionamiento, por considerado una respuesta parcial a los problemas de las mujeres, por el papel asistencialista que juegan e incluso por la profundización de la dependencia económica de "otras" que se genera. Distintas organizaciones de mujeres sostienen que resulta más positivo fortalecer las redes sociales de ayuda, apoyo y solidaridad, así como creer en la potencia y la fuerza de las mujeres, aunque no niegan su valor en situaciones de emergencia.

d) Las oficinas legales y consultorios jurídicos: Por un lado informan a las mujeres sobre sus derechos y alientan la denuncia de malos tratos, y por el otro lado, reciben las denuncias de mujeres golpeadas e inician las demandas otorgándoles asesoramiento y asistencia jurídica durante toda la duración del procesamiento legal. Asimismo, existen experiencias de formación y capacitación de promotores o consejeras legales que sin ser abogadas, tienen un conocimiento básico de la ley y de las normas procesales y que trabajan en sectores populares, un ejemplo de esto lo encontramos en los cursos para promotores realizada por el movimiento Manuela Ramos. Estas experiencias como instrumento fundamental de apoyo a las victimas, en consideración de la poca cercanía que hay entre las mujeres y la ley, y lo desventajosos que son las legislaciones y los sistemas jurídicos, en general para la población femenina.

e) Comisaría de Mujeres: Atendidas por personal policial femenino especialmente capacitado y entrenado para recibir y acoger las denuncias de las mujeres golpeadas, asumiendo que la violencia contra la mujer es un problema específico que requiere tratamiento diferenciado. Estas iniciativas son un importante avance, ya que a partir de un espacio policial especializado las mujeres obtienen una mejor atención, están más estimuladas para denunciar ya que no se sienten indefensas. Y debido a que se toman medidas los agresores se inhiben más en su conducta abusiva. La presencia de estas comisarías es un reconocimiento por parte del Estado y 
de la sociedad de que la violencia contra la mujer existe y es un delito que hay que prevenir y castigar.

En lo que se refiere a estrategias de prevención la médico Ana Guiller propone tres etapas: primero, concientizar a la población para que modifique su actitud frente a una mujer golpeada, segundo, sensibilizar a los agentes del Estado, y tercero, brindar a la mujer golpeada asistencia psicológica y legal.

Otra propuesta mucho más amplia es la de difundir un tipo de relación de pareja basada en la igualdad, Así pues, se hace una comparación entre una relación basada en la igualdad y otra basada en el poder y en el control.

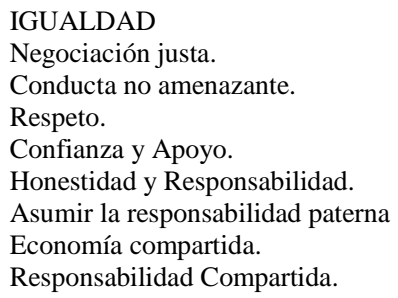

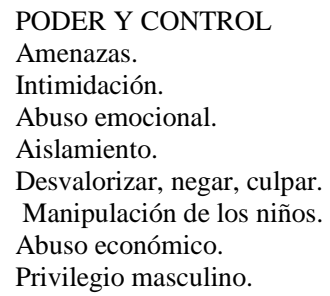

Asimismo, si ampliáramos aún mas esta visión, estaríamos hablando de una cultura sin violencia familiar definida en los siguientes términos:

a) Respeto básico mutuo.

b) Controles formales e informales contra la agresión.

c) Opciones para expresar las emociones sin violencia.

d) Igualdad entre los sexos sin diferencias en su trabajo ni su importancia.

La gravedad del problema de la violencia doméstica, debido a su magnitud, su extensión y a las serias consecuencias individuales y sociales, requiere de acciones urgentes y del diseño de estrategias preventivas. Las raíces de la violencia contra la mujer al interior de la familia sin estructurales 10 que hace imprescindible implementar políticas para 
modificar aquellas estructuras que conducen a la violencia y a su perpetuación, creando un ambiente propicio para la igualdad entre los sexos, el respeto por la dignidad de las personas y el desarrollo con equidad.

Las medidas que se deben tomar no pueden circunscribirse a un área específica sin que deban involucrar a distintos actores sociales desde una perspectiva integral. Estas acciones deben ser implementadas en forma simultánea, independientemente de si los efectos son a corto o largo plazo, para así enfrentar el problema en todos sus condicionantes.

\section{CONCLUSIONES}

1. En la mayoría de los casos de violencia conyugal en nuestro medio el agresor es el hombre, y la ofendida la mujer.

2. El fenómeno de la violencia en la pareja, e intrafamiliar, no es privativo de un grupo social más favorecido, sino que esta presente en todos los estratos y niveles socio-económicos con diferentes matices en cada uno de ellos.

3. La violencia en la pareja e intra familiar no es de etiología única sino multicasual y esta influenciada tanto por factores internos como externos de cada uno de los miembros individualmente, como pareja y como grupo. Muchos de ellos han sido violentados de niños.

4. La violencia en la pareja no se presenta como un fenómeno aislado sino que involucra y afecta a todas las personas que conforman el grupo ya sea directa o indirectamente.

5. La violencia en la pareja no pasa sin repercusiones; además de las perturbaciones físicas y principalmente psicológicas y emocionales que producen en los individuos afectados, se repite y perpetua a través de las generaciones.

6. Por su alta incidencia la violencia en la pareja constituye un motivo de preocupación desde el punto de vista médico-forense y jurídico. El considerarla únicamente a la luz del código penal (delito de lesiones 
personales) ha demostrado ser poco operante y uno de los factores que contribuyen a que se presente una marcada reincidencia. Debe tenerse en cuenta este aspecto al redactar el Código del Menor y la Familia y buscar soluciones al mismo tiempo, no solo desde el punto de vista punitivo, sino principalmente epidemiológico (prevención, rehabilitación) pero además por un mecanismo de identificación va a llevar a que posteriormente se produzca la misma situación al formar sus propias familias. Recordemos que la función de socialización de la familia se basa esencialmente en la internalización que hace el niño de ciertos papeles o roles familiares, y la importancia que tiene el ambiente familiar en el desarrollo sociológico del niño.

\section{BIBLIOGRAFÍA}

Baca, M. E. (1989). Tristeza, Miedo y Vergüenza ante el castigo físico y verbal.. Mujer y sociedad. 9 (28), 12-16.

Corsi, J. (1989). Aspectos psicosociales y asistencia les del hombre golpeador.

Ponencia al Seminario Violencia familiar, mujer golpeada. Buenos Aires.

Corporación casa de la mujer (1988). Violencia en la intimidad de la mujer.

Bogotá: Gente Nueva.

Delegacion de mujeres de Arequipa (1993). Violencia doméstica. Informe estadístico de la Comisaria de mujeres. Arequipa: Instituto Laboral para el Desarrollo Regional.

Deza, S. (1996). La dinámica subjetiva de la violencia en mujeres: un acercamiento a la integración del trabajo Psicológico y Legal (Folleto). Lima: IDEFAVI.

Espinoza, L. (1990). La Violencia Enmascarada. Revista viva. (17), 8-9.

Ferreira, G. (1995). Una mujer desvalorizada (Folleto). Lima: DEMUS.

Hamann, M. E. (1995). Lógica de una modalidad de relación amorosa (Folleto). Lima: DEMUS.

Olier, L. (1992). Mujeres golpeadas. Trabajo presentado en el 3er. Congreso Feminista Latinoamericano y del cambio, Sao Paulo.

Vicente, E. (1985). ¿Licencia para violar a la mujer? Mujer-ILET 46.

Vila de Garlic, M. C. (1988, Junio).Ciclo de la violencia conyugal. Ponencia al Seminario Violencia familiar, mujer golpeada. Buenos Aires.

Vila de Garlic, M. C. (1989, Octubre). Creencias sociales que sustenta la violencia hacia la mujer. Ponencia al Seminario Violencia familiar, mujer golpeada. Buenos Aires. 